\title{
Assessing the Impacts of Vegetation Cover Change in Mahazat Alsayd Natural Reserve Using Remote Sensing and Ground-Truth Data
}

\author{
Ali A. Al-Namazi and Khalid A. Almalki
}

\begin{abstract}
Saudi Arabia is located within an arid to semi-arid region, however, it is a biological diverse area, because species have adapted to the adverse ecological circumstances. One of the most important habitats in Saudi Arabia is the Mahazat Alsayd natural reserve. Understanding changes in vegetation cover over time is important for studying the habitats present in the reserve, and for analyzing the availability of animal fodder, as well as the extent of vegetation regeneration. Using remote sensing data and field observations, we detected that the vegetation coverage of Mahazat Alsayd decreased by $80 \%$ from 1995 to 2015. Multiple factors are currently affecting the structure of the plant and animal communities within the reserve. Such factors include ecological changes and human activities. These factors might lead to the extinction of some plant and/or animal species in the near future, either directly or indirectly. Thus, a comprehensive management plan must be implemented in the reserve as soon as possible to maintain and recover vegetation to provide sufficient animal feed, facilitating the sustainable conservation of animals and plants within the reserve. The vegetation cover assessment presented here provides an important source of information for conservation planning.
\end{abstract}

Index Terms-Conservation, natural reserve, remote sensing, vegetation.

\section{INTRODUCTION}

Natural reserves, or protected areas, in Saudi Arabia have been established since the 1970s to protect a group of environmentally integrated systems. One of these protected areas is Mahazat Alsayd "Fig. 1", which is the second largest natural reserve worldwide, and has been protected by the Saudi Wildlife Authority (SWA) since 1987. Mahazat Alsayd is located in central-west Saudi Arabia "Fig. 1". The reserve covers an area of about 218,793 ha. It was mainly established for the re-introduction of the houbara bustard (Chlamydotis [undulata] macqueenii) [1], and to breed certain endangered species, such as the Arabian oryx (Oryx leucoryx) [2]-[4] and sand gazelles (Gazella subgutturosa marica), in their natural habitat [5]. The animals that receive the most protection in this nature reserve are the sand fox and sand cat [6], several rodent species, and several birds species, such as the Lappet-faced vulture (Torgos tracheliotus), Egyptian vulture (Neophron percnopterus), Griffon vulture

Manuscript received July 25, 2019; revised January 24, 2020. This work was supported by King Abdulaziz City for Science and Technology (KACST) and the Saudi Wildlife Authority (SWA).

The authors are with the King Abdulaziz City for Science and Technology (KACST), Saudi Arabia (e-mail: alnamazi@gmail.com, kmalki99@gmail.com).
(Gyps fulvus) [7], the brown-necked raven (Corvus ruficollis) [8], the Arabian ostrich (Struthio camelus syriacus) [9] and several eagles, and reptiles [10].

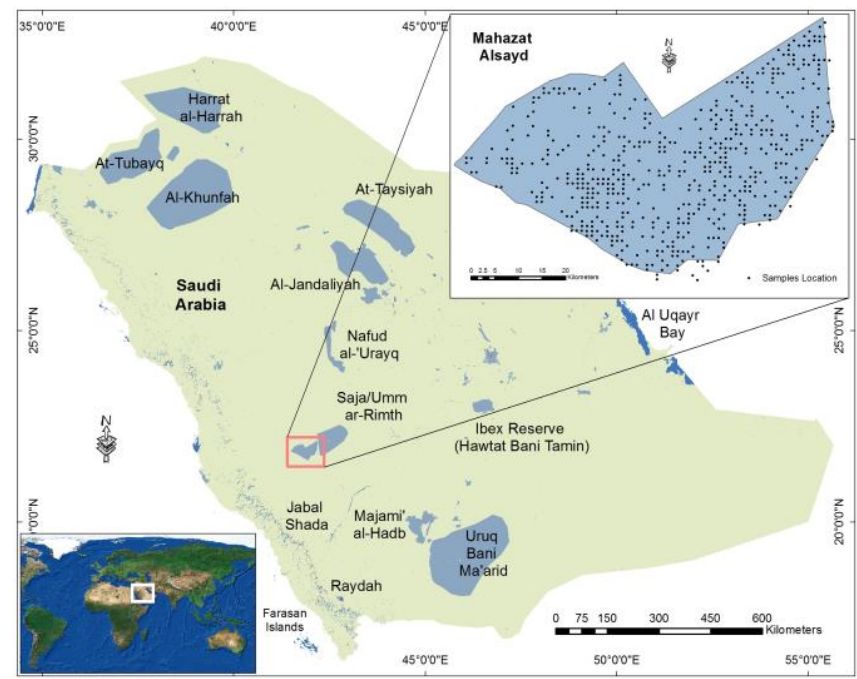

Fig. 1. Location and distribution of nature reserves and protected areas in Saudi Arabia. The inset shows the location where field samples were collected within the Mahazat Alsayd nature reserve.

Establishing Mahazat Alsayd reserve also helped preserve plant species on the verge of extinction, resulting in it now contains high plant diversity [3], [5]. The vegetation covering the reserve consists mostly of trees, shrubs, herbs, and grasses that are adapted to arid and semi-arid environments. To date, 112 species belonging to 38 families have been reported in Mahazat Alsayd nature reserve [11]. About 55\% of these species are perennial and about $45 \%$ are annual [12]. Some of the major species within the reserve are Acacia ehrenbergiana Hayne, Acacia nubica Benth., Acacia tortilis (Forssk.), Ajuga arabica P.H. Davis, Anastatica hierochuntica Linn., Corchorus depressus Linn., Cressa cretica Linn., and Enneapogon desvauxii P. Beauv.

Understanding the distribution, availability, and evolution of vegetation is important for understanding whether animals have access to sufficient nutrition within a given area, which, in turn, influences the success of conservation actions. In arid and semi-arid environments, the composition and structure of vegetation changes due to several biotic and abiotic factors. Overgrazing is one of the most important biotic factors affecting vegetation composition in these environments [13], [14]. In arid environments, abiotic factors, such as environmental conditions (e.g., drought, temperature, and salinity), contribute to observed changes in vegetation composition [15], [16]. Furthermore, human activities, such as mining, construction, tree cutting, and bush burning, 
potentially affect the environment and vegetation [17], [18].

Remote sensing has become one of the most efficient tools used to study vegetation communities and monitor the state of rangelands [19], [20]. In 1995, the SWA obtained the first map of the vegetation covering Mahazat Alsayd reserve using SPOT satellite XS data and field observations [21]. In the present study, we used remote sensing techniques and field-collected data to the present to map and examine the evolution of the vegetation cover in Mahazat Alsayd natural reserve over the last 20 years. Although that we are using the same techniques been used for the previous study, our present study expand the last effort by using higher resolution satellite images as well as collecting new data and exploring the relationships between multiple ecological indicators. Our results are expected to provide insights on how the vegetation cover has changed over this 20 -year period. Based on our results, we consider the possible major factors contributing to these changes, including climate change in this particular region, and propose potential long-term vegetation recovery plans.

\section{Materials AND Methods}

This study used SPOT-5 satellite data (images with $2.5 \mathrm{~m}$ resolution) of the Mahazat Alsayd area obtained in 2015 "Fig. $2 \mathrm{a}$ " to apply the normalized difference vegetation index (NDVI). In addition to the Spot images, we have obtained the recent Shuttle Radar Topography Mission (SRTM) satellite data (30-meter resolution) [22] for Mahazat Alsayd in order to create a digital terrain model and a flow accumulation model. The area was covered by four scenes (rows 305 and 306 in path 138, and rows 305 and 306 in path 139). The SPOT-5 images were acquired in four spectral bands (B1: green, B2: red, B3: near infrared, and B4: short wave infrared), with a spatial resolution of $10 \mathrm{~m}$ for bands 1,2 , and 3, $20 \mathrm{~m}$ for band 4, and $2.5 \mathrm{~m}$ for the panchromatic band. The wavelength of the SPOT- 5 bands ranged between $0.48 \mu \mathrm{m}$ and $1.75 \mu \mathrm{m}$. All images were registered using the Universal Transverse Mercator (UTM) coordinate system, zone 37, and were rectified with the World Geodetic System (WGS) 84. In addition, a mosaic of two or more overlapping images was applied to create a single image representation of the entire area "Fig. 2a".

The normalized difference vegetation index (NDVI) technique [23] was applied to the SPOT-5 data to determine the current vegetation density in the reserve. The use of satellite imagery to produce a NDVI dataset to assess and quantify vegetation cover is a well-documented procedure [24], [25]. This index derives from the difference in reduction and reflectance properties of vegetation in the red and near-infrared bands provided by satellite data [26]. The NDVI model was calculated based on the following formula:

$$
N D V I=N I R-R E D / N I R+R E D
$$

where: NIR represents the Atmospherically corrected Near-Infrared band and RED represents Atmospherically corrected Red band.

The flow accumulation model of Mahazat Alsayd area based on the SRTM data was determined by accumulating the weight for all cells that flow into each downslope cell. Method of calculating the accumulated flow from digital elevation data is well known [27].

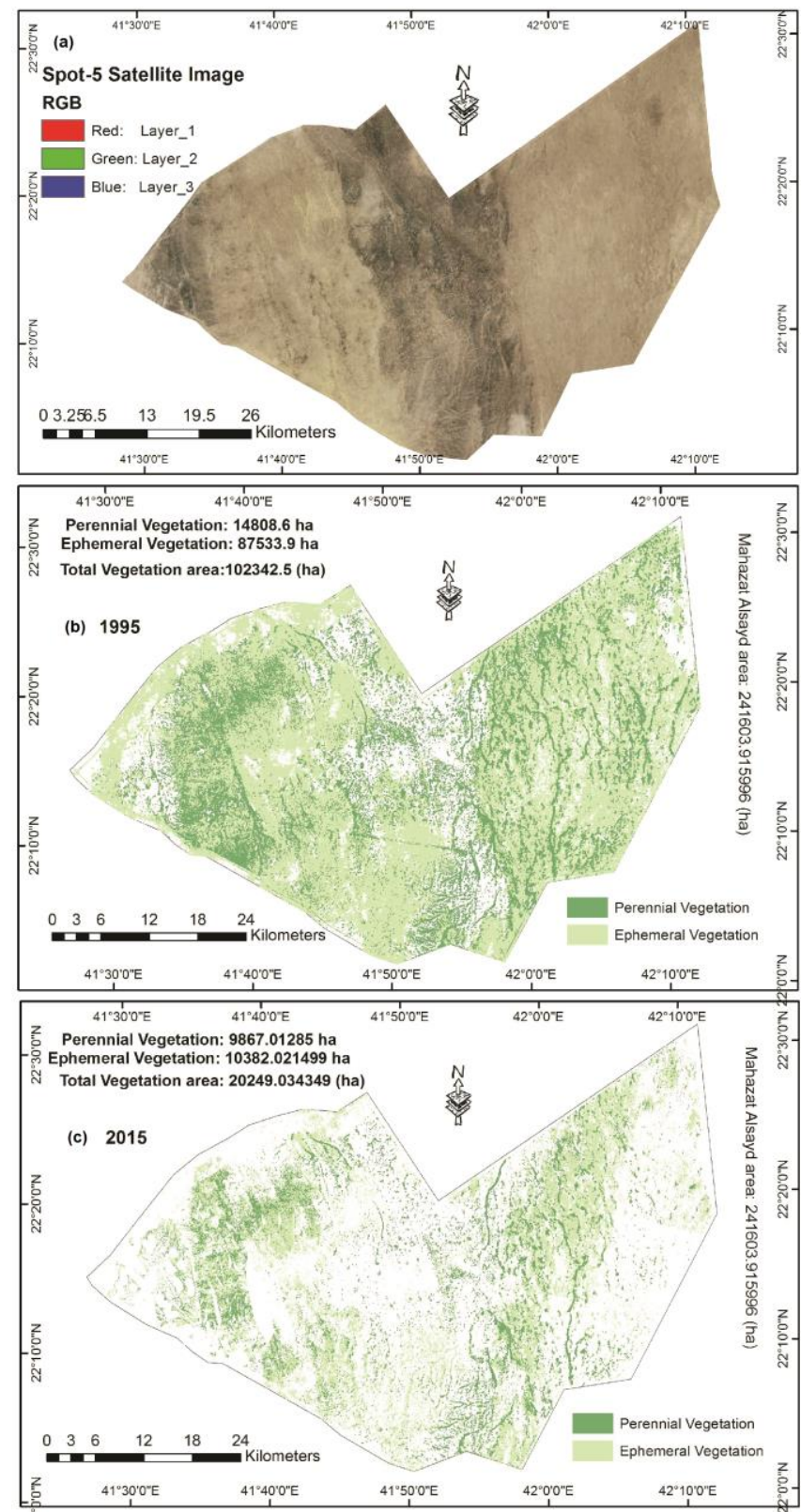

Fig. 2. Mahazat Alsayd satellite image and perennial and ephemera vegetation map based on remote sensing and ground-truth data. (A) SPOT-5 satellite image of Mahazat Alsayd nature reserve. (B) Vegetation map produced from the Spot XS image (June 7, 1995) modified from NRERI (1997). (C) Vegetation map produced from the data obtained in the present study.

Selected observations and samples from key localities were obtained to ground-truth the vegetation cover and different plants within the Mahazat Alsayd reserve as well as soil features. The purpose of the fieldwork was to validate the different image signatures (soil, vegetation, water, etc.) and to correct or edit the NDVI map manually to increase model accuracy. Field data were collected between June 1 and June 14, 2015 from 600 locations "Fig. 1" that were randomly selected and surveyed to classify plant species into perennial and ephemeral vegetation. Although randomly selected, these locations covered most of the reserve vegetation areas.

Climate data between 1995 and 2015 were obtained from 
several sources to analyze climate change. Such sources included the data provided by the SWA's local weather station located within Mahazat Alsayd reserve and the Climate Change Knowledge Portal provided by The World Bank Group for overall Saudi Arabia average monthly temperatures and rainfall. Climate data from the local Mahazat Alsayd weather station were collected between 2013 and 2015 only by the SWA's. A graph was created to present climate information using these data, and the relationship between temperature and rainfall data. It should be noted that the local weather station is the only station available at the area and that next station is located about 170 $\mathrm{km}$ from Mahazat Alsayd reserve and thus has not been used.

\section{RESULT}
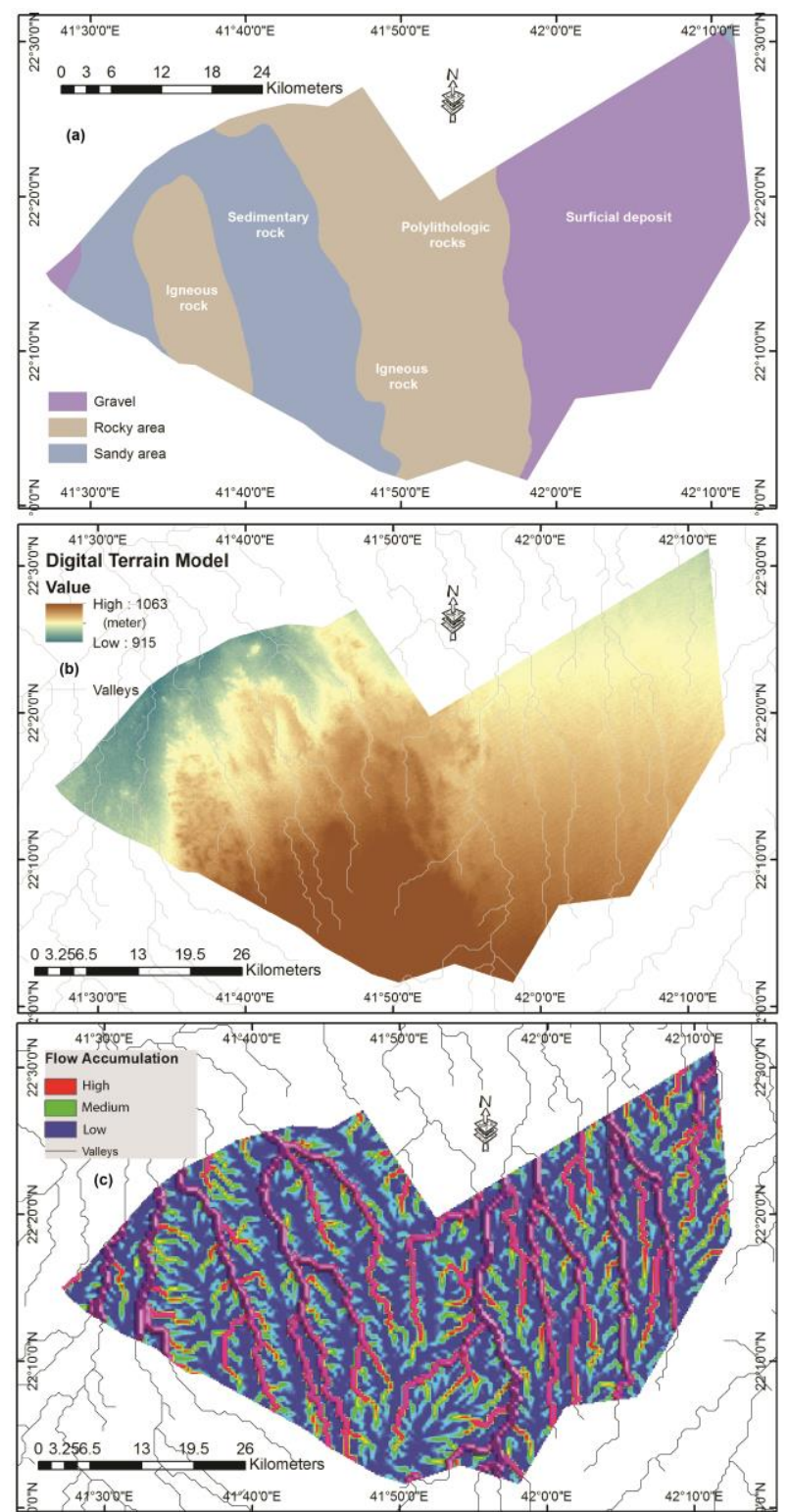

Fig. 3. Thematic map and raster images showing soil classification, elevation features and flow model of the reserve. (A) Map of different soil type. (B) Digital terrain model ( $\sim 30$ meter resolution). (C) Flow accumulation model.

The SWA study completed in 1995 reported a total vegetation cover of $102,342.5$ ha, including $14,808.6$ ha of perennial vegetation and 87,533.9 ha of ephemeral vegetation based on NDVI technique and field observations
"Fig. 2b" [21]. In contrast, the current study detected an area of 20,249.03 ha of total vegetation cover, including 9,867.01 ha of perennial vegetation and 10,382.02 ha of ephemeral vegetation "Fig. 2c". Thus, the remote sensing and field data reported here indicate a reduction of at least $80 \%$ vegetation cover in Mahazat Alsayd reserve in the last 20 years, including a $33 \%$ decrease in perennial vegetation and an $88 \%$ decrease in ephemeral vegetation.
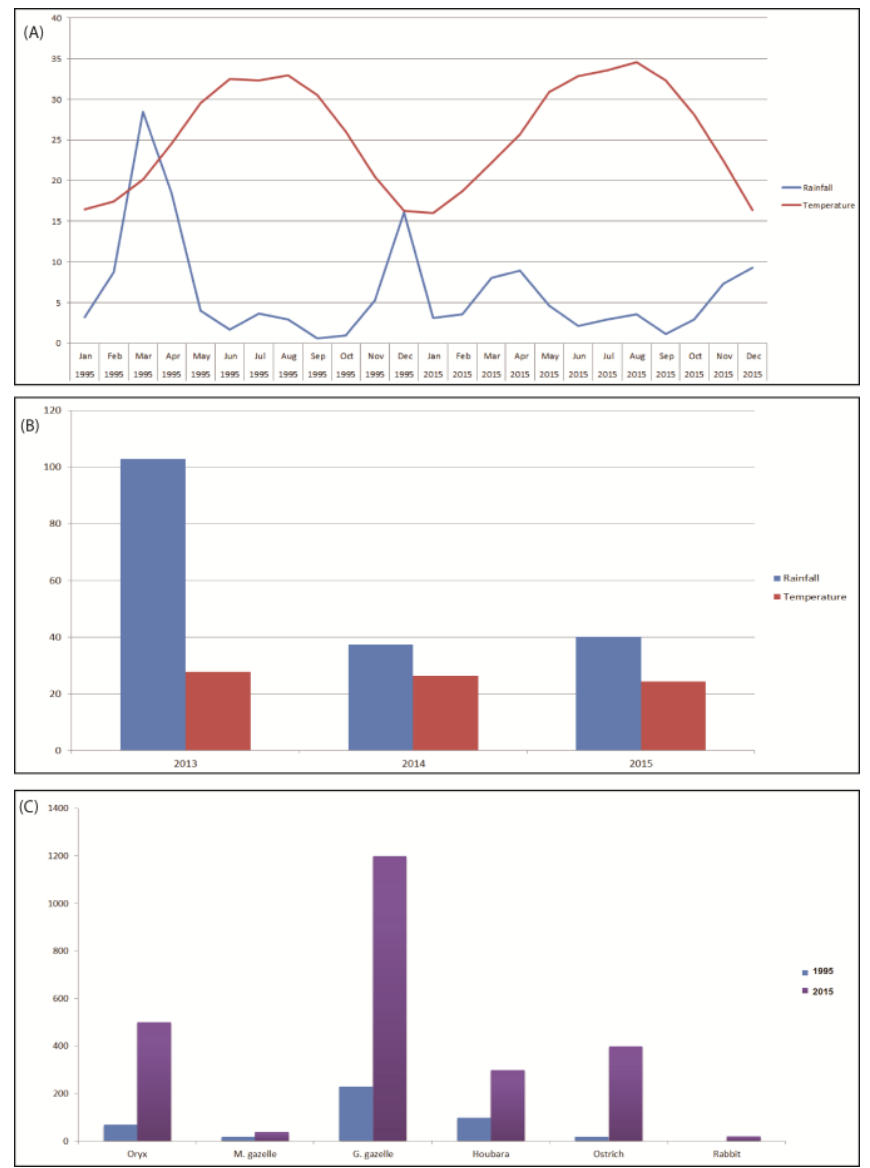

Fig. 4. Temperature and rainfall rate and animal species of Mahazat Alsayd nature reserve. (A) Average temperature (in Celsius) and rainfall (in millimeters) in Saudi Arabia at 1995 and 2015 retrieved from the Climate Change Knowledge Portal, (B) Average temperature (in Celsius) and rainfall (in millimeters) at Mahazat Alsayd between 2013 and 2015 according to the data of the weather station placed at the study area (Saudi Wildlife Authority provided the data), and (C) Animal species found in the Mahazat Alsayd nature reserve and their abundance in 1995 and 2015, according to SWA data. Climate

(https://climateknowledgeportal.worldbank.org/country/saudi-arabia).

The soil type has been classified into three categories: 1) Sand, 2) Rocks, and 3) gravel "Fig. 3a" based on direct field observations and constrained by available geological information [28]. In correlation to the geology of the area, the soil map shows a good correlation with the nature of the rock classifications in Mahazat Alsayd. It is evident from current vegetation distribution that the vegetation cover is more constraints in the sandy or gravelly areas. Sandy and gravelly areas are usually correlated with sedimentary or surficial deposits "Fig. 3a".

Based on the digital terrain model "Fig. 3b", it is inferred that the Mahazat Alsayd area has an elevation ranging between 915 and 1063 meters above sea level. Yet the eastern area of the Mahazat Alsayd shows a low topographic relief. The stream network based on the flow accumulation model 
"Fig. 3c" suggests that the flow direction will usually run from south to north or north-west. Identified stream channels from the flow accumulation model suggest that the high flow accumulation areas are associated with highly density vegetation cover.

Climate data of Saudi Arabia shows an overall sharp decrease in average rainfall rate and slight increase in average temperature between 1995 and 2015 "Fig. 4a". The reserve usually receives less than $100 \mathrm{~mm}$ of rainfall yearly based on the local weather observations "Fig. 4b". The average monthly minimum and maximum temperatures ranged from 2 to $21{ }^{\circ} \mathrm{C}$ and 29 to $40{ }^{\circ} \mathrm{C}$, respectively [29]. This result supported the data reported for 1995-2015, which were retrieved from the Climate Change Knowledge Portal. The recent data collected by the SWA station at the reserve is consistent with the whole country condition as it showed a noticeable decrease in rainfall between 2013 and 2015 "Fig. $4 \mathrm{~b}$ ". Thus, the analysis of climate data suggested a significant climate change, with an estimated $62 \%$ decrease in rainfall between 1995 and 2015, although the average air temperature in 2013-2015 was similar to that between 1995 and 2015.

\section{DISCUSSION}

Previous studies documented that the vegetation coverage in Mahazat Alsayd reserve noticeably recovered between 1989 and 1994, after the area was fenced [5]. However, our results demonstrated a remarkable decline in the vegetation cover of the reserve from 1995 to 2015 . The drop of $80 \%$ in total vegetation cover is a robust indicator of vegetation degradation within the reserve, which could threaten the survival of the wildlife that it supports. Ephemeral vegetation coverage declined by about $88 \%$, however, this type of vegetation is not a clear indicator of the vegetation status, because ephemeral vegetation is continuously changing, due to seasonal climate fluctuations [30]. However, there was also a remarkable decrease in perennial vegetation coverage (about 33\%), with this change illustrating major vegetation degradation and the poor condition of rangelands within the reserve. This decline in vegetation coverage might be due to several abiotic (e.g., environmental changes), biotic (e.g., grazing), and/or human (e.g., mining and overcutting of trees for firewood) factors. The results of the present study indicate that these multiple factors have led to the observed decline in vegetation cover, and have had a substantial impact on the structure of vegetation communities.

Environmental changes play a fundamental role in modifying vegetation structure and composition [31]. Analysis of climate data suggested there was a remarkable decrease in precipitation within the reserve. For instance, average annual rainfall sharply decreased from about 100 $\mathrm{mm}$ in 2013 to about $37 \mathrm{~mm}$ in 2014 and $40 \mathrm{~mm}$ in 2015 "Fig. $4 \mathrm{~b}$ ". Although climate data showed almost stable temperature signatures in the reserve, overall surface observations from various sources show that the temperature has significantly increased between 1994 and 2009 in Saudi Arabia [32]. The decrease in the rate of annual rainfall and the increase in temperature indicate that the study area has been subject to a drought period, which might have had a remarkable impact on the ephemeral vegetation, but not necessarily on the perennial vegetation, because some perennial species can endure longer periods of dryness [33], [34].

The SWA has managed to increase the number of animals inside the reserve from 1995 to 2015 "Fig. 4c" [35]. Increasing the number of animals, particularly herbivorous animals (e.g., oryx and gazelle) has generated pressure on palatable species [36]. The negative impact of grazing pressure increases with increasing aridity [37], and this increasing grazing pressure on palatable species might have led to the decline in vegetation cover, affecting plant community structure and diversity within the reserve. Ultimately, the abundance of palatable species might greatly decrease, or even become extinct [38], as in case of the palatable species Lasiurus scindicus that was recorded in 1990 [11], but was not found in 2011 [12] or in the present study. Animal carrying capacity increases with time, enhancing the pressure on palatable species. Consequently, the plant community structure becomes dominated by unpalatable species (i.e., toxic and spinescent) [39]. This phenomenon causes a shortage in the supply of animal forage, especially in the absence of annual species during droughts [40]. Therefore, some of the wild animals in the reserve might die of starvation, which was corroborated to some extent by the large number of animals that died during the drought period (1999-2009) [41]. Drought has also been suggested as the direct cause of animal death in the Mahazat Alsayd reserve [42]. Thus, it is urgent to manage the animal carrying capacity of this reserve to protect palatable plant species from extinction.

Overgrazing and human activities, such as mining and cutting trees, have a negative effect on vegetation, especially in arid and semi-arid environments [43]. According to the SWA, well excavations related to mining activity have been conducted in the reserve for about 15 years. Thus, mining activities might have a highly negative impact on the vegetation of this area in the near future, particularly in the northeastern part where these activities are intense. Mining activities are considered responsible for the deterioration of micro and macro organisms and vegetation in several countries [44].

\section{Conclusions}

Our study demonstrates the importance of remote sensing technology as an effective tool to monitor key aspects of biodiversity, such as vegetation state over time, especially within nature reserves. This kind of technology allows information to be collected in a timely and cost-effective manner that is fundamental for developing effective policies. In a wide and semi-hard terrain area, such as the Mahazat Alsayd reserve, we were able to reduce field work time by using satellite images. These images were used to build a digital information database that can be updated in the future.

The lack of management in the Mahazat Alsayd reserve, and at reserves around the world with similar environmental conditions, will certainly lead to the loss of biodiversity [45], [46] as evidenced by the deterioration of vegetation and animal life shown for Mahazat Alsayd reserve. In fact, the degradation of vegetation in Mahazat Alsayd reserve is an example of the impact of certain human activities on many 
nature reserves in arid and semi-arid regions. Such activities had a noteworthy impact on natural reserves worldwide, even in temperate environments [47], [48]. Thus, aggression caused by human activities or exploration (e.g. mining) will only speed up biodiversity loss in natural reserves.

Mahazat Alsayd reserve is a major contributor to the conservation of rare animal and/or plant species in Saudi Arabia. For this reserve to be sustainable, a proper management plan must be established, with regular assessments of the conservation status of the animals that use it [49]. Various recovery plans have been tested and conducted in natural reserves worldwide [50]-[53] that could be implemented by the SWA. Such initiatives would have environmental and habitat impacts. Further, one of the most important contributions outside the scope of the actual, or direct, administration is the raising of societal awareness about the importance of the Mahazat Alsayd reserve as a contributor to the preservation of both ecological and environmental balance.

Among the recommendations that might help recover the state of vegetation in the Mahazat Alsayd reserve and similar reserves around the world, the first is strict governance. This approach is urgently needed to plan regulations that constrain the harmful human activities. Mining activities, for instance, must be banned or, at least, regulated to reduce their negative impact on the reserve's vegetation. Second, we emphasize that animal carrying capacity should be managed and regulated to reduce grazing pressure on vegetation. Based on our field observations, animals rely completely on vegetation and rainfall for their water consumption. Thus, it is important to introduce a regular water supply plan, especially during the drought season (between June and September), or, at least, consider a water management plan in case temperature in this area increases as predicted. Animals are usually concentrated near water resources; therefore, drinking water needs to be distributed at different points along the reserve area to reduce grazing pressure on vegetation in areas that have been degraded by overgrazing [54], [55]. Further, isolating the current non-vegetated or desertified areas and limiting access to particular places might help toward facilitating vegetation regeneration, allowing it to rehabilitate in the future. Finally, ecological restoration should be implemented in the degraded areas within the reserve. Continuous monitoring is essential to assess and evaluate the implications of these management policies.

\section{CONFLICT OF INTEREST}

The authors declare no conflict of interest.

\section{AUTHOR CONTRIBUTIONS}

Ali Al-Namazi and Khalid Almalki conducted the research, analyzed the data and wrote the paper; all authors had approved the final version.

\section{ACKNOWLEDGMENT}

King Abdulaziz City for Science and Technology (KACST) provided the satellite images. The authors thank the spatial information system unit team at the Natural and Environmental Research Institute, KACST, and the Saudi
Wildlife Authority (SWA) team for their support during fieldwork. The SWA provided climate and animal data. Special thanks are also due to Mr. Bader Almalki, the supervisor of Mahazat Alsayd protected area, for his support. The authors also thank anonymous reviewers for their comments that greatly improved the paper. This paper was presented at the 7th International Conference on Sustainable Environment and Agriculture (ICSEA 2019).

\section{REFERENCES}

[1] P. J. Seddon et al., "Restoration of houbara bustard populations in Saudi Arabia: Developments and future directions," Oryx, vol. 29, pp. 136-142, 1995.

[2] The 2000 IUCN Red List of Threatened Species, IUCN, Gland, Switzerland, 2001

[3] P. Vincent, Saudi Arabia: An Environmental Overview, Taylor \& Francis Group, London, UK: CRC Press, 2008.

[4] J. B. Williams et al., "Climate change and animals in Saudi Arabia," Saudi J. Biol. Sci., vol. 19, pp. 121-130, 2012.

[5] M. N. Haque and, T. R. Smith, "Reintroduction of Arabian sand gazelle Gazella subgutturosa marica in Saudi Arabia," Biol. Conserv., vol. 76, pp. 203- 207, 1995.

[6] A. H. Abuzinada, "The role of protected areas in conserving biological diversity in the kingdom of Saudi Arabia," J. Arid Environ., vol. 54, pp. 39- 45, 2003.

[7] M. Shobrak, "Changes in the number of breeding pairs, nest distribution and nesting trees used by the Lappet-faced Vulture Torgos tracheliotus in the Mahazat As-Sayd Protected Area, Saudi Arabia," Journal of the Bombay Natural History Society, vol. 108, no. 2, p. 114 , 2011.

[8] M. Shobrak, "Breeding success of brown-necked ravens corvus ruficollis in the Mahazat as-Sayd Protected Area, Saudi Arabia," Sandgrouse, vol. 27, pp. 152-156, 2005.

[9] M. Zafar-Ul Islam et al., "Re-introduction of the red-necked ostrich, Struthio camelus camelus, in Mahazat as-Sayd Protected Area in central Saudi Arabia," Zool. Middle East, vol. 44, pp. 31-40, 2008.

[10] M. Shobrak, "Ecology of the lappet-faced vulture in Mahazat as-Sayd reserve, Saudi Arabia," Ph.D. Thesis, University of Glasgow, Glasgow, 1996.

[11] H. Gillet, Vegetation Studies, Mahazat As Said Reserve, Saudi Arabia Taif: National Wildlife Research Center, 1990.

[12] Y. M. Al-Sodany et al., "Vegetation analysis of Mahazat Al-Sayd protected area: the second largest fenced nature reserve in the world," World Applied Sciences Journal, vol. 15, pp. 1144-1156, 2011.

[13] W. Y. Zhao et al., "Changes in vegetation diversity and structure in response to heavy grazing pressure in the northern Tianshan Mountains, China," Journal of Arid Environments, vol. 68, pp. 465-479, 2007.

[14] S. L. Al-Rowaily et al., "Changes in vegetation composition and diversity in relation to morphometry, soil and grazing on a hyper-arid watershed in the central Saudi Arabia," Catena, vol. 97, pp. 41- 49, 2012.

[15] S. E. Nicholson et al., "Desertification, drought, and surface vegetation: An example from the West African Sahel," Bulletin of the American Meteorological Society, vol. 79, pp. 815- 829, 1998.

[16] E. A. Bray et al., "Responses to abiotic stresses," Biochemistry and Molecular Biology of Plants, American Society of Plant Physiologists, Rockville, MD, 2000, pp. 1158-1249.

[17] Z. Batjargal, "Desertification in Mongolia," RALA Report 200, National Agency for Meteorology, Hydrology and Environment Monitoring, Mongolia, 1994

[18] H. D. Musa and S. N. Jiya, “An assessment of mining activities impact on vegetation in Bukuru Jos Plateau State Nigeria using normalized differential vegetation index (NDVI)," Journal of Sustainable Development, vol. 4, pp. 150-159, 2011.

[19] S. L. Egbert et al., "Using conservation reserve program maps derived from satellite imagery to characterize landscape structure," Comput. Electron Agr., vol. 37, pp. 141-156, 2002.

[20] C. He et al., "Zoning grassland protection area using remote sensing and cellular automata modeling - A case study in Xilingol steppe grassland in northern China," Journal of Arid Environments, vol. 63, pp. 814-826, 2005

[21] NRERI, "Wild life conservation management and monitoring by remote sensing and geographic information system (GIS), vegetation map of Mahazat As Sayd," King Abdulaziz City for Science and 
Technology, Natural Resources and Environment Research Institute, Report No. 101/17/SI, 1997.

[22] J. J.Becker et al., "Global bathymetry and elevation data at 30 arc seconds resolution: SRTM30_PLUS," Marine Geodesy, vol. 32, no. 4, pp. 355-371, 2009.

[23] J. Rouse Jr et al., "Monitoring vegetation systems in the Great Plains with ETS," Third ERTS Symposium, NASA, SP-351 I, pp. 309-317, 1974.

[24] A. J. Elmore et al., "Quantifying vegetation change in semiarid environments: precision and accuracy of spectral mixture analysis and the normalized difference vegetation index," Remote Sensing of Environment, vol. 73, pp. 87-102, 2000.

[25] G. S. Boggs, "Assessment of SPOT 5 and QuickBird remotely sensed imagery for mapping tree cover in savannas," International Journal of Applied Earth Observation and Geoinformation, vol.12, pp. 217-224, 2010.

[26] T. Fung and W. Siu, "Environmental quality and its changes, an analysis using NDVI," Int. J. of Remote Sens, vol. 21, pp. 1011-1024, 2000.

[27] D. G. Tarboton, R. L. Bras, and I. Rodriguez-Iturbe, "On the extraction of channel networks from digital elevation data," Hydrological Processes, vol. 5, pp. 81-100, 1991.

[28] P. R. Johnson, "Explanatory notes to the map of proterozoic geology of Western Saudi Arabia," Technical Report, SGS-Tr-2006-4, 2006.

[29] F. Penati and P. Vienna, "An updated catalogue of the Histeridae (Insecta: Coleoptera) of the Arabian Peninsula, with biogeographical remarks," Zootaxa, vol. 1157, pp. 1-74, 2006.

[30] M. W. Talbot et al., "Fluctuations in the annual vegetation of California," Ecology, vol. 20, pp. 394-402, 1993.

[31] X. Zhang et al., "Climate controls on vegetation phenological patterns in northern mid- and high latitudes inferred from MODIS data. Glob," Change Biol., vol.10, pp. 1133-1145, 2004.

[32] M. Almazroui et al., "Recent climate change in the Arabian Peninsula: Seasonal rainfall and temperature climatology of Saudi Arabia for 1979-2009," Atmos. Res, vol. 111, pp. 29-45, 2012.

[33] J. P. Grime, Plant Strategies, Vegetation Processes, and Ecosystem Properties, London: Wiley, 1979.

[34] Z. Nie and M. R. Norton, "Stress tolerance and persistence of perennial grasses: The role of the summer dormancy trait in temperate Australia," Crop Science, vol. 49, pp. 2405-2411, 2009.

[35] A. C. Treydte et al., "In search of the optimal management strategy for Arabian oryx," Anim. Conserv., vol. 4, pp. 239-249, 2001.

[36] J. L. Maron and E. Crone, "Herbivory: Effects on plant abundance, distribution and population growth," in Proc. the Royal Society Lond, Biol. Sci., vol. 273, pp. 2575-2584, 2006.

[37] D. J. Eldridge et al., "Ecosystem structure, function and composition in rangelands are negatively affected by livestock grazing," Ecol. Appl., vol. 26, pp. 1273-1283, 2015.

[38] C. Riginos and M. T. Hoffman, "Changes in population biology of two succulent shrubs along a grazing gradient," J. Appl. Ecol., vol.40, pp. $615-625,2003$

[39] T. Kraaij and S. J. Milton, "Vegetation changes (1995-2004) in semi-arid Karoo shrubland, South Africa: Effects of rainfall, wild herbivores and change in land use," J. Arid Environ., vol. 64, pp. 174-192, 2006.

[40] S. J. Milton and M. T. Hoffman, "The application of state-and-transition models to rangeland research and management in arid succulent and semi-arid grassy Karoo, South Africa," Afr. J. Range For. Sci., vol.11, pp. 18-26, 1994.

[41] M. Z. Islam et al., "Catastrophic die-off of globally threatened Arabian Oryx and Sand Gazelle in the fenced protected area of the arid central Saudi Arabia," Journal of Threatened Taxa, vol.2, pp. 677-684, 2010a.

[42] M. Z. Islam et al., "Strategy and action plan to reduce the risk of mass mortalities of reintroduced ungulates in the Mahazat as-Sayd Protected Area in Saudi Arabia," GNUSLETTER IUCN, vol.28, pp. 9-15, 2010b.

[43] E. J. Arets et al., Assessment of the Impacts of Gold Mining on Soil and Vegetation in Brownsberg Nature Park, Suriname, Centre for
Ecosystem Studies, Wageningen, The Netherlands: Alterra, 2006, no. 1359.

[44] A. O. Eludoyin et al., "Effects of artisanal gold mining activities on soil properties in a part of southwestern Nigeria," Cogent Environmental Science, vol. 3, no. 1305650, p. 11, 2017.

[45] E. O. Hellmuth, "Eco-physiological studies on plants in arid and semi-arid regions in Western Australia: III. Comparative studies on photosynthesis, respiration and water relations of ten arid zone and two semi-arid zone plants under winter and late summer climatic conditions," J. Ecol., vol.59, pp. 225-259, 1971.

[46] M. Matsuki et al., "Impacts of dust on plant health, survivorship and plant communities in semi-arid environments," Austral Ecol., vol. 417 pp. 423-427, 2016.

[47] S. H. Marsh et al., "Detecting mine pollution using hyperspectral data in temperate, vegetated European environments," in Proc. the 14th ERIM Thematic Conference, Las Vegas, NV, pp. 552-555, 2000.

[48] C. Bernes et al., "What is the impact of active management on biodiversity in forests set aside for conservation or restoration? A systematic map," Environmental Evidence, vol.4, p. 25, 2015.

[49] D. Mallon and K. Budd, Regional Red List Status of Carnivores in the Arabian Peninsula, IUCN, Gland, Switzerland and Cambridge, UK and the Environment and Protected Areas Authority, Government of Sharjah, UAE, 2011, p. 49

[50] M. H. Murray et al., "Wildlife health and supplemental feeding: A review and management recommendations, Biol. Conserv., vol. 204, pp. 163-174, 2016.

[51] R. M. Perkl, “Geodesigning landscape linkages: Coupling GIS with wildlife corridor design in conservation planning," Landscape Urban Plan, vol. 156, pp. 44-58, 2016.

[52] S. W. Evans, "An assessment of land cover change as a source of information for conservation planning in the Vhembe Biosphere Reserve,"Appl. Geogr., vol. 82, pp. 35-47, 2017.

[53] C. Van Cuong et al., "Biosphere reserves: Attributes for success," J. Environ. Manage., vol.188, pp. 9-17, 2017.

[54] J. De Leeuw et al., "Distribution and diversity of wildlife in northern Kenya in relation to livestock and permanent water points," Biol. Conserv., vol. 100, pp. 297-306, 2001.

[55] G. Shannon et al., "The effects of artificial water availability on large herbivore ranging patterns in savanna habitats: A new approach based on modelling elephant path distributions," Divers. Distrib., vol. 15, pp. 776-783, 2009.

Copyright (C) 2020 by the authors. This is an open access article distributed under the Creative Commons Attribution License which permits unrestricted use, distribution, and reproduction in any medium, provided the original work is properly cited (CC BY 4.0).

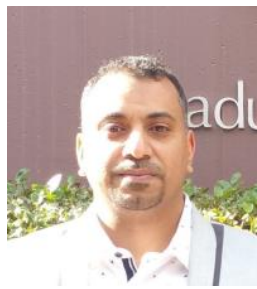

Ali Al-Namazi has a $\mathrm{PhD}$ degree in plant sciences from the University of New South Wales (UNSW) $\mathrm{He}$ is working as an assistant professor in the King Abdulaziz City for Sciences and Technology (KACST). His researches focus on plant ecology and plant conservation.

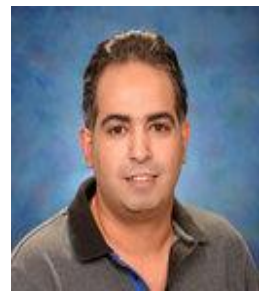

Khalid A. Almalki obtained his $\mathrm{PhD}$ from Monash University in 2013. He is working at King Abdulaziz City for Science and Technology as an associate research professor. His current research interests include geographic information system remote sensing and geophysical applications for geology, natural resources, public health and environmental management. He has published various papers in peer reviewed journals. 